\title{
On the Role of Imagination in the Use of History in Mathematics Education
}

\author{
Thomas De Vittori ${ }^{1 *}$ (D)
}

${ }^{1}$ Univ. Artois, UR 2462, Laboratoire de Mathématiques de Lens (LML), F-62300 Lens, FRANCE

*Corresponding Author: thomas.devittori@univ-lille.fr

Citation: De Vittori, T. (2021). On the Role of Imagination in the Use of History in Mathematics Education. International Electronic Journal of Mathematics Education, 16(3), em0660. https://doi.org/10.29333/iejme/11296

\begin{tabular}{|c|c|}
\hline ARTICLE INFO & ABSTRACT \\
\hline Received: 25 Apr. 2021 & 3ased on an experiment carried out with 10- to 11 -year-old pupils, this paper questions the place of imagination \\
\hline Accepted: 14 Sep. 2021 & $\begin{array}{l}\text { in a class activity using the history of mathematics. The study focuses on three groups of pupils who were offered } \\
\text { three variants of the same activity based on base- } 60 \text { counting (our time measurement system inherited from the } \\
\text { Babylonians). To identify differences and similarities between the three scenarios, a quantitative analysis, using a } \\
\text { Principal Component Analysis (PCA), was carried out on the basis of the pupils' productions and a questionnaire. } \\
\text { The approach remains exploratory, but it seems to indicate that imagination plays a relevant role in sessions using } \\
\text { history of mathematics. }\end{array}$ \\
\hline
\end{tabular}

Keywords: history of mathematics, imagination, mathematics education, primary school, quantitative study

\section{INTRODUCTION}

In recent decades, the use of history in mathematics education has become a fruitful specific research field. As established by Clark et al. (2019) in a review of recent works on what they call the "HPM perspective" (History and Pedagogy of Mathematics perspective), but after approximately thirty years since the first studies on the use of historical materials to teach mathematics (Clark et al., 2018; Fauvel, 1991; Fauvel \& Van Maanen, 2002; Furinghetti, 1997), many questions remain. For many years, the scientific community (Clark et al., 2019; Gulikers \& Blom, 2001) has emphasized that in addition to the quest for suitable theoretical frameworks (Fried et al., 2016), there is a need for empirical research to convincingly examine and evaluate the HPM perspective. Recent studies have made interesting findings on topics such as students' beliefs about mathematics (Bütüner, 2015a; Bütüner \& Baki, 2020) and methods for integrating history into mathematics education (Wang et al., 2018), but the pedagogical levers are still largely to be studied. Many methods are available for researching mathematics education (Blum et al. 2019), but there is a noticeable gap in the study of the HPM perspective. In particular, unlike in most education fields (Hansson et al., 2020; Nawani et al., 2018; Staus et al., 2020), quantitative approaches are underutilized in research on the use of the history in mathematics education. However, such methods could be highly relevant (Gras, 1992) for assessing the effectiveness of using history in mathematics education, studying some aspects of this approach, and providing meaningful and generative answers (Schoenfeld, 2020). For instance, it is generally thought using history as a means or as a purpose in education (Jankvist, 2009) increases student motivation and engagement in complex tasks (Heiede, 1992). Guillemette (Fried et al., 2016) recently suggested that use of history in mathematics education allows for the reconstruction and reinterpretation of the past, enabling new possibilities and mathematical creation. This point of view is similar to that in studies of history education (Hawkey, 2004) and science education (Hadzigeogiou et al., 2012), in which narratives have been identified as engines for learning. It thus seems legitimate to ask whether there is such a bridge between imagination and cognition (Nemirovsky \& Ferrara, 2009; Paixão \& Borges, 2018) within the HPM perspective as it can be identified in science learning (Hadzigeorgiou, 2014). Such a bridge could then be identified as one of the pedagogical drivers of the HPM approach. After reviewing the definition of imagination, this paper focuses specifically on the place of the imagination in the HPM perspective. The approach, which is based on data from a real experiment with pupils, is a quantitative one. Let us notice that quantitative studies of the use of history in mathematics education in the classroom are still a bit lacking, with the topic rarely studied by that mean (Bütüner, 2015b; Lemondis, 2016). This paper tends to modestly contribute to this part of the research field. 


\section{WHAT IS IMAGINATION?}

A brief review of the history of scientific and philosophical thinking (Archambault \& Venet, 2007; Nielsen et al., 2010) shows that understanding of imagination varies a lot by author and the period in which it is studied. It oscillates between a passive competence of reproducing reality in a more or less distorted way to an intellectual faculty of recombining ideas in what is sometimes called creative imagination. This latter position is the most interesting when the study is interested in learning. As Sauvageot (2002) points out, imagination represents another way of perceiving reality, another logic, necessary for a better understanding of the world. According to him, if the imagination is indeed a bank of all possible images, past, present and future, it is also the dynamic process according to which they are mentally produced, retained and transformed. The focus of this article is the imagination of children as they encounter a story in written, oral or real-life form. Concerning children and their psychology, the works of Piaget and Vygotsky are always instructive. On the specific question of imagination, these two authors oppose in having two very different theoretical readings.

According to Piaget (1972), the development of intelligence is organized around the progressive construction of rational and formal thinking from early childhood to adolescence. Imagination is conceived by Piaget as an antinomy of structured thinking. Archambault and Venet (2007) explain that Piaget opposes creative imagination and logical thinking. His research on cognitive development situates the most prolific period of imagination at the arrival of language, symbolic play and representative imitation. Nevertheless, since formal thinking is, according to Piaget, fully operative only towards adolescence, it is interesting to consider the role of the imaginary in structuring the thinking of pupils aged 10-11. The use of history in mathematics education, that is, the history of a past world that is forever inaccessible, does not seem dissimilar to the use of symbolic games that put a creative imagination to work. This is particularly striking when the task is to do mathematics like the ancients. Finally, Piaget has little regard for imagination because it does not participate productively in intelligence and is considered less important than means of representation that are more suited to reality (Piaget, 1972). He thus writes that the child has no imagination, and the imagination that common sense attributes to him is only a way of describing incoherence.

Unlike Piaget, who makes imagination a character of the small child, Vygotsky sees it as a process directly linked to the creation of meaning, that is, a superior psychological function that is linked not only to emotions but also to intellectual functions (Gajdamaschko, 2006). Thus, there is parallel development of rational and imaginary thinking until late adolescence. More precisely, the imagination of a teenager is closely related to conceptual thinking; it is intellectualized and included in the system in which it begins to fulfill a completely new function. This position questions the role of imagination in both children and adults. According to Vygotsky, imagination is a creative force that is stronger when it is based on rich experience. It is articulated around two phases, the first allowing the production of altered elements of thought from reality and the second proposing a recombination of these elements and past sensations into an imaginary production. In this process, for Vygotsky, who, let us remember, is one of the founders of socioconstructivism (Nielsen et al., 2010), the child or the adult is not alone. Development is part of social relationships (Gajdamaschko, 2006) that contribute to giving substance to imagination as a higher mental function (through the sharing of ideas, for instance). The adult, like the child, is capable of acting as if, which is important when proposing a mathematical learning situation that suggests a change of posture (taking the posture of the researcher or a scientist from the past) or conception (for example, conceiving of ideas or conceptions relating to concepts). Faced with a common understanding that makes imagination only the place for elucubrations about what does not exist, Vygotsky (2004) explains that imagination, as the basis of all creative activity, is an important component of absolutely all aspects of cultural life, particularly enabling artistic, scientific and technical creation. Within the framework of Vygotsky's theories, imagination, in its most accomplished form, manifests itself only with the mastery of concepts (Archambault \& Venet, 2007), which offers interesting perspectives in terms of experimentation or pedagogical practice. Indeed, by placing the outcome of the imagination on the side of the adult world, Vygotsky justifies the passage from a subjective imagination (the world of children's dreams and games) to an objective imagination that allows innovation and the creation of new scientific and technical ideas. To conclude this panorama of psychological reflections, it should be noted that recent research in this field tends to attribute a strong cognitive role to imagination from childhood. For Harris (2002), an important aspect of imagination is that it gives children the opportunity to act as if they are in a universe in which they interpolate within the imaginary situation the same causal processes and necessities that they know to be at work in reality. This idea recalls the words of Guillemette given in the introduction. In this sense, imagination can become the bearer of reasoning. Within the Vygotskian perspective, according to which stories can serve as tools to stimulate imagination, the question remains as to what types of stories we should use in the education of our pupils (Egan, 1992; Egan et al., 2016). Perhaps the history of mathematics has this ability to resonate with the creative imagination that Vygotsky (2004, p. 12) explicitly states as "this ability to combine elements to produce a structure, to combine the old in new ways that is the basis of creativity." In what follows, I will try to point out the role of the imagined story in the pedagogical functioning of a classroom situation.

\section{MATERIALS AND METHOD}

To explore the role of history in learning based on the history of mathematics, three versions of an activity for students (age 10-11) were developed. The first two include history (version 1 and version 2), and the third is without historical support (version 3). In all three cases, the scenario is organized around three successive stages: an activity specific to each scenario with the manipulation of the base- 60 system we use for time measurement, a series of decontextualized exercises common to all three versions, and finally a questionnaire. The purpose is mainly to compare the first two scenarios, as they both involve history. Let us detail the introductory activity, the exercise sheet, and the questionnaire. 
To minimize bias due to media variations, the two activities with a history component are identical in their organization, in the numbers and problem wording proposed, and in the tasks. The only difference lies in the real historical context of Babylonian mathematics (version 1) versus a fictitious context evoking an extraterrestrial civilization of the twenty-fourth millennium, the Zalussians (version 2). These modifications were made to the introductory and explanatory texts, one of the illustrative images, a name (a king) and the objects to be counted in the end-of-activity problem. For instance, the introduction is "Nearly 2000 years before our era, in a region called Mesopotamia (which corresponds to present-day Iraq), the civilization of the Babylonians developed a particular way of writing" in version 1, and "In the year 23045, in a galaxy called AKM-234-P, the Zalussian civilisation developed a special way of writing" in version 2 . The choice of a very distant date in the future and the use of clearly invented words for the galaxy and civilization in the story are intended to leave no doubt as to the imaginary nature of the situation in version 2. The anchoring in a fictional universe is further accentuated by an image representing an unknown planet and galaxy. On the other hand, the first image showing authentic cuneiform characters engraved in stone is identical for each of the two scenarios. For the rest of the activities, in both versions 1 and 2, cuneiform writing is presented in exactly the same way in the rules explanation, illustrating examples and application questions. Between the two versions, only the word "Babylonian" has been replaced by the word "Zalussian". It is important to notice that on the historical dimension, a number of simplifications have been made not only to make the content easily accessible to pupils but also to allow the development of tasks that are sufficiently similar to allow for a single didactic analysis. The first simplification concerns the civilizations. While the imaginary extraterrestrial civilization does not carry any constraints, referring to the Babylonians under a single heading is, in itself, very simplistic when describing human activities in Mesopotamia over nearly three millennia. Not wanting to create such a rich universe for the imaginary people, it was decided to evoke the Babylonians without going into detail. The second freedom taken with scientific knowledge of this period lies in the use of a form of number writing outside its historical scope. As Proust (2008) explains, several Babylonian numbering systems coexisted, including an additive system (for ordinary counting) and a positional system (for mathematical calculations). For reasons of proximity to our way of representing time (hours, minutes, seconds), the positional system was introduced in the classroom, even though the examples are more related to ordinary counting. The Babylonian cuneiform writing will lead the pupils to code the various groupings of units, then of sixty, and finally of sixty squared. In the activity, the conversion work is done on small numbers $(17 ; 44 ; 85 ; 201)$ to gradually approach the role of base 60 and the writing system. The exploration of the base- 60 writing system ends with a sentence explaining the extension of the rules beyond the first change of rank. The main objective is to make the connection with our hours/minutes/seconds system. The last part of the activity is a multiplicative problem followed by a comparison of two numbers $(25 \times 7=175$, and then comparing them to 196). As before, the presentations of the problems are strictly identical, and only the context is changed. At the end of this work on the sexagesimal system, the activity sheet presents a small paragraph that specifies, in both cases, the historical interest of this type of numbering. The present cultural contribution is thus maintained in all approaches by the history of mathematics. In the case of version 2 , the text is presented orally by the teacher. The third version of the introduction activity does not reference a story. There is no mention of the history of mathematics or a fictitious story, and the calculations are made directly in the hours/minutes/seconds system. Instead of the introduction of the Babylonian system, a sentence simply reminds us that in the writing system, 60 seconds equal 1 minute, and 60 minutes equal 1 hour. This sentence is followed directly by examples because there is no need to check the correct understanding of the signs used in writing. The numerical examples are, of course, the same as in the first two versions ( $85 \mathrm{~s}=1$ $\min 25 \mathrm{~s}$ and $201 \mathrm{~s}=3 \mathrm{~min} 21 \mathrm{~s}$ ). The exercises are in the form of classic conversion questions, and finally, the problem maintains the structure and values of versions 1 and 2, but the context is contemporary (phone conversation time).

The second step of our experimentation consists in determining whether the pupils are able to reinvest notions or methods seen during an activity with historical support. The exercise sheet thus includes two conversion exercises followed by a problem. Exercises 1 and 2 involve converting several durations into hours, minutes and seconds. In exercise 1, the values (18 min $85 \mathrm{~s} ; 70$ $\min 8 \mathrm{~s} ; 65 \mathrm{~min} 67 \mathrm{~s}$; and $124 \mathrm{~min} 72 \mathrm{~s}$ ) are chosen to show two of the three ranks of the $\mathrm{h} / \mathrm{m} / \mathrm{s}$ system. However, exercise 2 requires converting the times given into seconds $(3,212 \mathrm{~s} ; 4,000 \mathrm{~s} ; 7,290 \mathrm{~s} ; 11,000 \mathrm{~s})$ to gradually test whether the passage from one rank to another of the three ranks is correctly understood. Following these decontextualized tasks, exercise 3 presents a short multiplicative problem ( 8 times 25 minutes) and conversion problem without any historical support.

To evaluate this experiment, after the activity and exercises, the students were asked several questions. The questionnaire is multiple choice and built around two main themes. The first is school-based and concerns the pupils' feelings about the various exercises. In this theme, the students were asked to provide their overall opinions on the activity "How did you find this activity? Not interesting/Not very interesting/Quite interesting/Very interesting" and feedback on the perceived difficulty of each of the three school exercises via a five-point Likert scale (stars to be colored in, 1 star = very easy; 5 stars = very difficult). In data processing, these questions are supplemented with the results for each pupil using a scale for each exercise and question. Exercises 1 and 2 were graded on the basis of 0.25 points per correct answer, and exercise 3 was graded with 1 point if the problem was fully solved and 0.5 points if the final conversion was missing. The second theme of the questionnaire concerns the historical content of the activity and the pupils' use of history and imaginary worlds. For the historical content addressed in the activity, in scenarios 1 and 2, the first question concerns whether the student referenced the numbering system presented in the activity "Did you think about the Babylonian (Zalussian) numbering system to do the exercises? Not at all/A little/A lot." It should be noted that this question was poorly understood by the students, as shown by the large number of spontaneous questions asking what was expected. This lack of understanding is important for the subsequent processing of the questionnaire data. For scenario 3 , which does not include an exotic system, this question was not asked. On the subject of the history of mathematics present in the experiment, the pupils were asked about their desire to learn more: "Would you like to know more about the mathematics of the Babylonians (resp. Zalussians) and their history? No/Yes, a little/Yes/Yes, I'm very interested." For Scenario 3, this question was modified to connect it to the complements made by the teacher at the end of the activity. A short five-line text explaining the role of the Babylonian civilization in our system of time measurement is followed by the question "Would you like to know more about 
Table 1. Quality of representation of the variables $\left(\cos ^{2}\right)$. Values greater than 0.3 are in bold

\begin{tabular}{|c|c|c|c|c|c|}
\hline & Dim.1 & Dim.2 & Dim.3 & Dim.4 & Dim.5 \\
\hline Ex1 & 0.83 & 0.00 & 0.01 & 0.02 & 0.00 \\
\hline Ex2 & 0.68 & 0.00 & 0.01 & 0.08 & 0.07 \\
\hline Ex3 & 0.74 & 0.01 & 0.00 & 0.08 & 0.03 \\
\hline DiffEx1 & 0.55 & 0.00 & 0.06 & 0.01 & 0.00 \\
\hline DiffEx3 & 0.42 & 0.07 & 0.07 & 0.00 & 0.26 \\
\hline Docs & 0.09 & 0.17 & 0.49 & 0.16 & 0.01 \\
\hline Movies & 0.02 & 0.51 & 0.01 & 0.15 & 0.16 \\
\hline Adventure & 0.00 & 0.84 & 0.00 & 0.00 & 0.01 \\
\hline Strategy & 0.02 & 0.58 & 0.13 & 0.01 & 0.00 \\
\hline Action & 0.11 & 0.66 & 0.02 & 0.02 & 0.02 \\
\hline Books-Comics & 0.21 & 0.06 & 0.28 & 0.29 & 0.09 \\
\hline Magazines & 0.00 & 0.03 & 0.81 & 0.01 & 0.00 \\
\hline
\end{tabular}

mathematics and its history? No/Yes, a little/Yes/Yes, I'm very interested." The end of the questionnaire is designed to evaluate the amount of time students spend on activities involving history or stories. For the series of six activities listed below, students were asked to indicate the average amount of time they spend per week on these activities: "How much time per week, on average, do you spend on (NB: each item is the subject of a separate question) watching documentary videos (history, science, etc.); watching films, series or cartoons; playing adventure or role-playing video games; playing strategy or management video games; playing action, sports or fighting games; reading books or comics; and reading magazines." The pupils chose the relevant time slot from a table: "Less than 1 hour (i.e., less than $10 \mathrm{~min}$ per day)/3-4 hours (approx. $30 \mathrm{~min}$ per day)/7-8 hours (approx. 1 hour per day)/14-15 hours (approx. 2 hours per day)/more than 15 hours (more than 2 hours per day)." As D'Amato (2007) points out, what makes video games particularly attractive is the possibility for users to become the protagonist of the stories and to act in the first person by changing the course of events. The world of video games is made up of fantasy, and video games are increasingly becoming one of the dominant leisure activities for children, especially adolescents and preadolescents. Therefore, this digital leisure activity was included in our questionnaire as a different option from reading books and watching films.

Despite their qualitative aspects, which seem to be easier for students to understand, the various answer options in the questionnaire are organized on a Likert scale. This makes processing easy because all the answers only have to be recoded (for example, from 0 for "No" to 3 for "Yes, I'm very interested") and inserted into a table. As the experiment was conducted in MayJune 2020, the implementation was strongly dependent on the COVID-19 pandemic and the health measures linked to the gradual return of pupils to the classroom after confinement. As only half class work was possible, a group of 10 pupils were presented the authentic historical story, and a group of 10 pupils were presented the fictional story. A final group of 9 pupils from a neighboring school were presented the scenario without historical support. In each of the situations, students worked individually on separate tables according to the imposed social distancing measures. Each group was thus fully separated from the others, which was pedagogically complex for the teachers but very useful for such comparative research.

\section{RESULTS}

Based on the data collected, a principal component analysis (PCA) was performed to identify general trends and determine whether the three scenarios contributed in the same way. Data were processed by the statistical calculation software R (R Core Team, 2020) with the FactoMineR package (Lê et al., 2008). The data table includes one qualitative variable (the scenario version) and sixteen quantitative variables that correspond to the evaluations of the decontextualized exercises and the answers to the questionnaire. In the PCA, the first variable is used as an additional variable. Due to the significant comprehension difficulties it generated and the fact that it is relevant only for versions 1 and 2, the variable corresponding to the question "Have you thought about the system (...)" was removed. Even if they did not create comprehension difficulties, variables corresponding to the questions about the global interest in the activity and about the desire to know more about the civilization involved were separated to be analyzed complementary to the PCA. These questions provided useful information on the way the pupils experienced the activities. For the final set of variables, following Beavers et al.'s (2013) recommendations, the variable corresponding to the felt difficulty of the second exercise was removed to obtain an acceptable Kaiser-Meyer-Olkin (KMO) index. For the remaining twelve items, the KMO value was 0.66 , which makes a significant PCA possible. The Bartlett test yielded $\chi^{2}=$ $149.17, \mathrm{df}=11$ and p-value $<2.2 \mathrm{e}-16$, which indicates interitem correlations in this dataset. The Kaiser-Guttman criterion seems to suggest a 3-component solution (with eigenvalues greater than 1). These 3 factors would explain $70.659 \%$ of the variance of all items.

The values in Table 1 give the weight of the variables for each factor. The PCA clearly separates a first dimension comprising the school mathematics components (Ex1, Ex2, Ex3, DiffEx1, DiffEx3) and a second dimension mainly driven by history and imagination (Movies, Adventure, Strategy, Action). The third dimension is also related to history but is not correlated to the set of variables in dimension 2. By construction, all dimensions are orthogonal to each other; that is, the dimension of mathematics content is fully decorrelated to dimension 2 and dimension 3, which deal with history and imagination. The books-comics variable does not significantly contribute to any of the first dimensions. Its indistinct combination of books and comics may explain this irrelevancy. Cronbach's alpha index confirms the item coherence in the first two dimensions, with values of 0.87 for dimension 1 and 0.82 for dimension 2 , but not in the third dimension, with a value of only 0.64 for dimension 3 . 


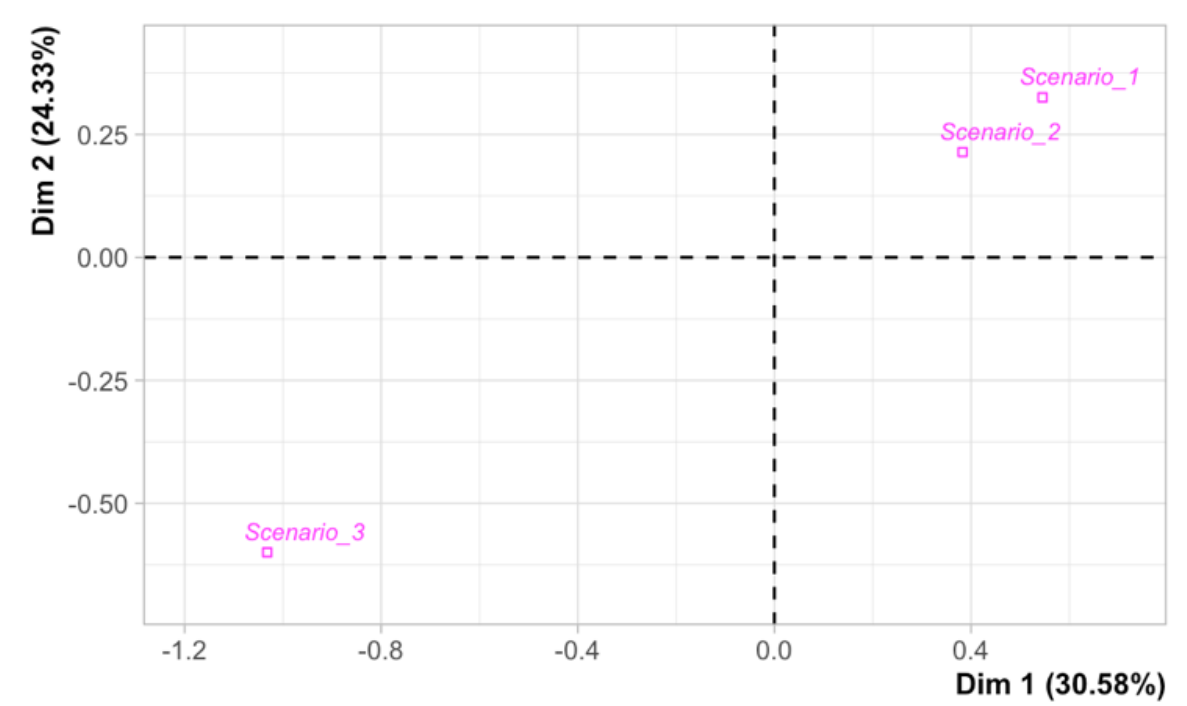

Figure 1. Graph of the individuals with only the supplementary qualitative variable "Scenario"

Table 2. Means for "Interest" and "KnowMore"

\begin{tabular}{cccc}
\hline & Interest & KnowMore & \\
\hline Version 1 & 3.75 & 3.4 \\
\hline Version 2 & 3.5 & 3.5 \\
\hline Version 3 & 3.0 & n/a \\
\hline
\end{tabular}

In the PCA, the first two dimensions express $54.91 \%$ of the total dataset inertia. This percentage is relatively high, and thus, the first plane well represents the data variability. This value is greater than the reference value of $37.76 \%$, and the variability explained by this plane is thus significant (Husson et al., 2016).

The graph of the individuals (Figure 1) shows a strong proximity of the first two versions of the activity (in the first quadrant) and a separation from the third version without historical content (in the third quadrant). To further explore the proximity of versions 1 and 2 (one with authentic historical content and the other with fictious content), variables measuring the felt global interest for the activity (Interest) and the desire to know more (KnowMore) about the civilization were compared. The means are given in Table 2 and have nearly same values as in version 1 and version 2. A small gap seems to appear between the first two scenarios and the third.

The variables are not normally distributed across groups, so a Wilcoxon test was used. For the Interest variable, this test reveals no significant difference between version 1 and version 2 ( $p$-value $=0.2926)$. There was a significant difference between version 1 and version 3 ( $p$-value $=0.02157$ ) but not between version 2 and version 3 ( $p$-value $=0.1739)$. For the KnowMore variable, the Wilcoxon test shows no difference between versions 1 and 2 ( $p$-value $=0.5794)$.

\section{DISCUSSION}

The experiment detailed above was not designed to evaluate the impact of different scenarios in terms of progress on school success with pre/post tests, for example. The analysis therefore does not focus on this aspect, which remains to be studied by other means. It should nevertheless be noted that the orthogonality of dimensions 1 (mathematics) and 2 (imagination/history) could mean that the pupils' experiences of the stories did not influence the activity. In the end, this may be good news because it may justify using an activity with historical support for all pupils, regardless of their background. The initial question in this paper concerns the way history of mathematics takes part of the pedagogical repertoire of teacher and, in a way, how it works in class. As mentioned in the introduction, the use of the history of mathematics has several potentialities which are fairly consensual. One of them is its capacity to create what Guillemette (Fried et al., 2016) calls a reorientation (dépaysement in French). The experiment conducted and described in this article was built with a view to testing the validity of this hypothesis by confronting two forms of historical narratives, one anchored in Human history, the other purely fictional. The graph of individuals in the PCA shows the very weak separation of the two scenarios. This indistinction means that, for this experimentation, the authenticity of the historical content has no impact on the students' experiences. How does this result inform us on the pedagogical function of history of mathematics? How does history of mathematics contribute to the way pupils enter the activity? The data are still too fragmentary to draw definite conclusions, but the lack of separation of scenarios 1 and 2, which both share a narrative part, suggests that one of the driving forces behind the functioning of some HPM approaches lies in their assumed anchorage in an imaginary universe (that of our ancestors). Within this universe, as Vygotsky suggests, pupils can experiment with new ways of thinking, which then feed into the present. In this sense, imagination, whose definition I still borrow from Vygostky, plays a catalytic role, which is very natural in young children, to enable a mathematical activity to be experienced with a historical background. The conclusion that 
seems to emerge from the PCA is that, in an approach based on the history of mathematics, what predominates with young students is an anchoring in the imaginary suggested by the media independent of the nature of history at stake. This point could partly explain the success of the use of history in mathematics education that has been noted by teachers and researchers as the added value of the imaginary thus seems to nourish but also transcend the use of the history of mathematics. What I have previously called imagination anchoring is a way of expressing this role played by imagination in the students' taste for any activity that involves this dimension. The HPM approach, when it takes a form similar to the one used as a basis for activities 1 and 2 (i.e., with the evocation of a dated context, a civilization, etc.), is undoubtedly part of this staging of the targeted knowledge and the tasks expected from the pupils. Despite limitations due to its small scale, the study presented in this article reminds us that the HPM perspective shares many points with other pedagogical approaches. Kotsopoulos and Cordy (2009) consider imagination as a cognitive space for learning but they notice that finding a way to create effective teaching situations is not so easy. Deeply related to the epistemological construction of concepts over time, the HPM perspective can help identify good resources for such an imaginary journey into a space conducive to learning. Imagination becomes then a way to activate the bridge (De Vittori, 2018) created by history of mathematics between conceptions from the past and contemporary school teaching.

Author contributions: All authors have sufficiently contributed to the study, and agreed with the results and conclusions.

Funding: No funding source is reported for this study.

Declaration of interest: No conflict of interest is declared by authors.

\section{REFERENCES}

Archambault, A., \& Venet, M. (2007). Le développement de l'imagination selon Piaget et Vygotsky: d'un acte spontané à une activité consciente [The development of the imagination according to Piaget and Vygotsky: from a spontaneous act to a conscious activity]. Revue des sciences de l'éducation, 33(1), 5-24. https://doi.org/10.7202/016186ar

Beavers, A. S., Lounsbury, J. W., Richards, J. K., Huck, S. W., Skolits, G. J., \& Esquivel, S. L. (2013). Practical considerations for using exploratory factor analysis in educational research. Practical Assessment, Research \& Evaluation, 18(6), 1-13. https://doi.org/10.7275/qv2q-rk76

Blum, W., Artigue, M., Mariotti, M. A., Sträßer, R., \& Van den Heuvel-Panhuizen, M. (2019). European traditions in didactics of mathematics. Springer International Publishing Imprint, Springer. https://doi.org/10.1007/978-3-030-05514-1

Bütüner, S. Ö. (2015a). Impact of using history of mathematics on students mathematics attitude: A meta-analysis study. European Journal of Science and Mathematics Education, 3(4), 337-349. https://doi.org/10.30935/scimath/9442

Bütüner, S. Ö. (2015b). Using history of mathematics to teach volume formula of frustum pyramids: Dissection method. Universal Journal of Educational Research, 3(12), 1034-1048. https://doi.org/10.13189/ujer.2015.031213

Bütüner, S. Ö., \& Baki, A. (2020). The use of history of mathematics in the mathematics classroom: An action study. International Journal of Education in Mathematics, Science and Technology (IJEMST), 8(2), 92-117. https://doi.org/10.46328/ijemst.v8i2.843

Clark, K. M., Kjeldsen, T. H., Schorcht, S., \& Tzanakis, C. (2019). History of mathematics in mathematics education - An overview. Mathematica Didactica, 42(1), 1-26. https://doi.org/10.1007/978-3-319-73924-3_1

Clark, K. M., Kjeldsen, T. H., Schorcht, S., \& Tzanakis, C. (Eds.). (2018). Mathematics, education and history, Towards a harmonious partnership. Springer. https://doi.org/10.1007/978-3-319-73924-3

D’Amato, M. (2007). L'imaginaire proposé par les jeux vidéo [The imaginary offered by video games]. Le Télémaque, 32(2), 73-82. https://doi.org/10.3917/tele.032.0073

De Vittori, T. (2018). Analyzing the use of history in mathematics education: Issues and challenges around Balacheff's cK $\ell$ model. Educational Studies in Mathematics, 99(2), 125-136. https://doi.org/10.1007/s10649-018-9831-6

Egan, K. (1992). Imagination in teaching and learning. University of Chicago. https://doi.org/10.7208/chicago/9780226244136.001.0001

Egan, K., Bullock, S., \& Chodakowski, A. (2016). Learning to teach, imaginatively: Supporting the development of new teachers through cognitive tools. McGill Journal of Education, 51(3), 999-1012. https://doi.org/10.7202/1039625ar

Fauvel, J. (1991). Using history in mathematics education. For the Learning of Mathematics, 11(2), 3-6.

Fauvel, J., \& van Maanen, J. (Eds.). (2002). History in mathematics education: The ICMI study, New ICMI Study Series (vol. 6), Springer. https://doi.org/10.1007/0-306-47220-1

Fried, M. N., Guillemette, D., \& Jahnke, H. N. (2016). Theoretical and/or conceptual frameworks for integrating history in mathematics education. In L. Radford, F. Furinghetti, \& T. Hausberger (Eds.), Proceedings of the 2016 ICME Satellite Meeting of the International Study Group on the Relations Between the History and Pedagogy of Mathematics (pp. 211-230). IREM de Montpellier. https://hal.archives-ouvertes.fr/HPM2016

Furinghetti, F. (1997). History of mathematics, mathematics education, school practice: Case studies in linking different domains. For the Learning of Mathematics, 17(1), 55-61.

Gajdamaschko, N. (2006). Theoretical concerns: Vygotsky on imagination development. Educational Perspectives, 39(2), 34-40.

Gras, R. (1992). L'analyse des données: une méthodologie de traitement de questions de didactique [Data analysis: a method for the processing of didactic questions]. Recherches en Didactique des Mathématiques, 12(1), 59-72. https://revuerdm.com/1992/l-analyse-des-donnees/ 
Gulikers, I., \& Blom, K. (2001) "A historical angle”, a survey of recent literature on the use and value of history in geometrical education. Educational Studies in Mathematics, 47(2), 223-258. https://doi.org/10.1023/A:1014539212782

Hadzigeorgiou, Y. (2014). Imagination and learning science. In R. Gunstone (Ed.), Encyclopedia of science education. Springer, Dordrecht. https://doi.org/10.1007/978-94-007-6165-0_465-2

Hadzigeorgiou, Y., Klassen, S., \& Klassen, C. F. (2012). Encouraging a "romantic understanding" of science: The effect of the nikola tesla story. Science \& Education, 21(8), 1111-1138. https://doi.org/10.1007/s11191-011-9417-5

Hansson, L., Hansson, Ö., Juter, K., \& Redfors, A. (2020). Curriculum emphases, mathematics and teaching practices: Swedish upper-secondary physics teachers' views. International Journal of Science and Mathematics, 19, $499-515$. https://doi.org/10.1007/s10763-020-10078-6

Harris, P. L. (2002). Penser à ce qui aurait pu arriver si... [Think about what could have happened if...]. Enfance, 54(3), 223-240. https://doi.org/10.3917/enf.543.0223

Hawkey, K. (2004). Narrative in classroom history. Curriculum Journal, 15(1), 35-44. https://doi.org/10.1080/1026716032000189461 Heiede, T. (1992). Why teach history of mathematics? The Mathematical Gazette, 76(475), 151-157. https://doi.org/10.2307/3620388 Husson, F., Lê, S., \& Pagès, J. (2016). Analyse de données avec $R$ [Data analysis with R]. Presses Universitaires de Rennes.

Jankvist, U. T. (2009). A categorization of the "whys" and "hows" of using history in mathematics education. Educational Studies in Mathematics, 71(3), 235-261. https://doi.org/10.1007/s10649-008-9174-9

Kotsopoulos, D., \& Cordy, M. (2009). Investigating imagination as a cognitive space for learning mathematics. Educational Studies in Mathematics, 70, 259-274. https://doi.org/10.1007/s10649-008-9154-0

Lê, S., Josse, J., \& Husson, F. (2008). FactoMineR: An R package for multivariate analysis. Journal of Statistical Software, 25(1), 118. https://doi.org/10.18637/jss.v025.i01

Lemondis, C. (2016). The use of history of mathematics in mathematics education, MENON Conline Journal of Educational Research, 2nd thematic issue, May, 2016. http://www.edu.uowm.gr/site/node/526

Nawani, J., Kotzebue, L., Rixius, J., Graml, M., \& Neuhaus, B. (2018). Teachers' use of focus questions in German biology classrooms: A video-based naturalistic study. International Journal of Science and Mathematics, 16, $1431-1451$. https://doi.org/10.1007/s10763-017-9837-z

Nemirovsky, R., \& Ferrara, F. (2009). Mathematical imagination and embodied cognition. Educational Studies in Mathematics, 70(2), 159-174. https://doi.org/10.1007/s10649-008-9150-4

Nielsen, T. W., Fitzgerald, R., \& Fettes, M. (Eds.). (2010). Imagination in educational theory and practice: A many-sided vision. Cambridge Scholars Pub.

Paixão, G. M., \& Borges, F. T. (2018). Imagination and educational curriculum: A literature review. Psicologia: Teoria e Pesquisa, 34, e34310. https://doi.org/10.1590/0102.3772e34310

Piaget, J. (1972). La formation du symbole chez l'enfant. Imitation, jeu et rêve, image et représentation [The formation of the symbol in childhood. Imitation, play and dream, image and representation]. Delachaux et Niestlé.

Proust, C. (2008). Quantifier et calculer : usages des nombres à Nippur [Quantifying and calculating: uses of numbers in Nippur]. Revue d'Histoire des Mathématiques, 14, 143-209. http://www.numdam.org/item/RHM_2008__14_2_143_0/

R Core Team (2020). R: A language and environment for statistical computing. R Foundation for Statistical Computing, Vienna.

Sauvageot, A. (2002). Imaginaire (structures et mécanismes de l'). In A. Mucchielli (Ed.), Dictionnaire des méthodes qualitatives en sciences humaines et sociales [Dictionary of qualitative methods in the humanities and social sciences]. Armand Colin.

Schoenfeld, A. H. (2020). On meaningful, researchable, and generative questions. International Journal of Science and Mathematics Education, 18, 67-82. https://doi.org/10.1007/s10763-020-10068-8

Staus, N. L., Lesseig, K., Lamb, R., Falk, J., \& Dierking, L. (2020). Validation of a measure of STEM interest for adolescents. International Journal of Science and Mathematics, 18, 279-293. https://doi.org/10.1007/s10763-019-09970-7

Vygotsky, L. S. (2004). Imagination and creativity in childhood. Journal of Russian and East European Psychology, 42(1), 7-97. https://doi.org/10.1080/10610405.2004.11059210

Wang, K., Wang, X., Li, Y., \& Rugh, M. S. (2018). A framework for integrating the history of mathematics into teaching in Shanghai. Educational Studies in Mathematics, 98(1), 135-155. https://doi.org/10.1007/s10649-018-9811-x 